\title{
A STUDY ON HIGH ROOF DRY DUST COLLECTOR MACHINE
}

\author{
Contractor Asifali A. \\ Department of Instrumentation and Control \\ Maratha Vidya Prasarak Samaj's Karmaveer \\ Adv. Baburao Ganpatrao Thakare College of \\ Engineering, Nashik, Maharashtra, India
}

\author{
Bedis Prachi K. \\ Department of Instrumentation and Control \\ Maratha Vidya Prasarak Samaj's Karmaveer \\ Adv. Baburao Ganpatrao Thakare College of \\ Engineering, Nashik, Maharashtra, India
}

\begin{abstract}
In industries the clean, functional workspace strengthens facility production, creates a healthier working environment, and complies with all Occupational Safety and Health Administration requirements. Cleaning is the most important part because dust particles can cause harm to the process of the industry.

It may reduce the efficiency of the instruments and the product may also fail because of these dust particles. Therefore, cleaning of high industrial roof is necessary, after a certain period of time. The high roof dry dust cleaning machine (HRDDCM) will help to clean fine particles and dry dust particles and consider a major factor whereas industry have high roofs, where human manual cleaning might cost to life risk. HRDDC utilizes explosion-proof manually operated vacuum systems to remove this dust safely from high ceilings.
\end{abstract}

Keywords - Industrial dust cleaning, Industrial dry vacuum cleaner (IDVC), High shade cleaning.

\section{INTRODUCTION}

Cleaning is very essential in every industry, as the dust can damage the products that are manufactured in the industry, and cause harm to the workers also. Therefore, a system is to be designed for cleaning the finite dust particles present on the roofs and shades of industry, more over the designed machine should operate from ground level with minimum cleaning labor efforts and avoiding the risk factor of cleaning labor's life.

The High Roof Dry Dust Collector Machine (HRDDCM) is a manual cleaning operating machine which is the safest and most effective way of cleaning the ceiling of the industries up to the height of 15 meters, walls and as well as the ventilation systems available in the industries. In addition to this the machine also cleans the places were ordinary cleaning machines are not reachable. The designed machine is operated from ground level, so it is safer and cost gets reduced. We can adjust the wide range of specialist brushes, tools and accessories to efficiently clean the difficult to reach areas.

A vacuum cleaner structure having self-propelling means. A handle is associated with the vacuum cleaner and the self- propelling means to drive the vacuum cleaner in accordance with force applied forwardly or rearwardly to the handle [4]. A vacuum cleaner comprising a housing and a base unit pivotally attached to each other, a motor and motor housing disposed within the base unit, a drive assembly also disposed within the base unit and selectively coupled to the motor, a nested wand releasable retained along the exterior of the housing, a lower air conduit extending between the base unit and a lower end of the wand, and an upper air conduit extending between an upper end of the wand and a suction chamber defined within the housing[5].

\section{LITERATURE SURVEY}

[1]The present invention relates to a remote controlled robot $\&$ control system for cleaning inner-walls of a duct, more particularly, to a remote controlled robot and a control system for effectively cleaning side walls, ceiling wall and bottom wall of a duct in spite of the slope change of the duct and for easily checking the cleaning state of a duct in real-time as well as after cleaning process, thereby enhancing the cleaning state of the duct as well as reducing cleaning time.

[2] JP6091771B2 discloses a cleaning cart comprising a fixed support rod for holding a brush arrangement comprising side brushes, bottom brushes and top brushes.

[3] US3800358A discloses a self-propelled vehicular apparatus for cleaning the interior wall surfaces of a rectangular duct having horizontal top and bottom walls and vertical side walls, in combination, a chassis, transport means engageable with said bottom wall and tractional supporting the chassis there above for movement there along, a reversible drive motor mounted on said chassis and operatively connected to said transport means in driving relationship, a suction pump mounted on said chassis adjacent to the forward end thereof and having an air inlet and an air outlet, an actuating motor on said chassis and operatively connected to the suction pump, a filter receptacle removably secured to said suction pump and in communication with said air outlet, and a brush-carrying suction head removably secured to said suction pump. 


\section{International Journal of Engineering Applied Sciences and Technology, 2020 \\ Vol. 5, Issue 2, ISSN No. 2455-2143, Pages 137-140 \\ Published Online June 2020 in IJEAST (http://www.ijeast.com)}

[4] JP2007-34561A In the self-propelled cleaner and the program, no consideration is given to dust that is rolled up during cleaning, particularly dust that includes particles such as dust and minute sand that is invisible. Since most of the cleaning by the self-propelled cleaner is performed in a cleaning area that is a sealed space, the dust that has been wound up after the cleaning accumulates on the floor.

\section{SYSTEM CONCEPT}

\section{Problem statement}

In industries the cleaning is the most important part because dust particles can cause harm to the process of the industry. It may reduce the efficiency of the instruments and the product may also fail because of these dust particles. The cleaning of fine particles and dry dust particles is considered a major factor whereas industry have high roofs, where human manual cleaning might cost to life risk.

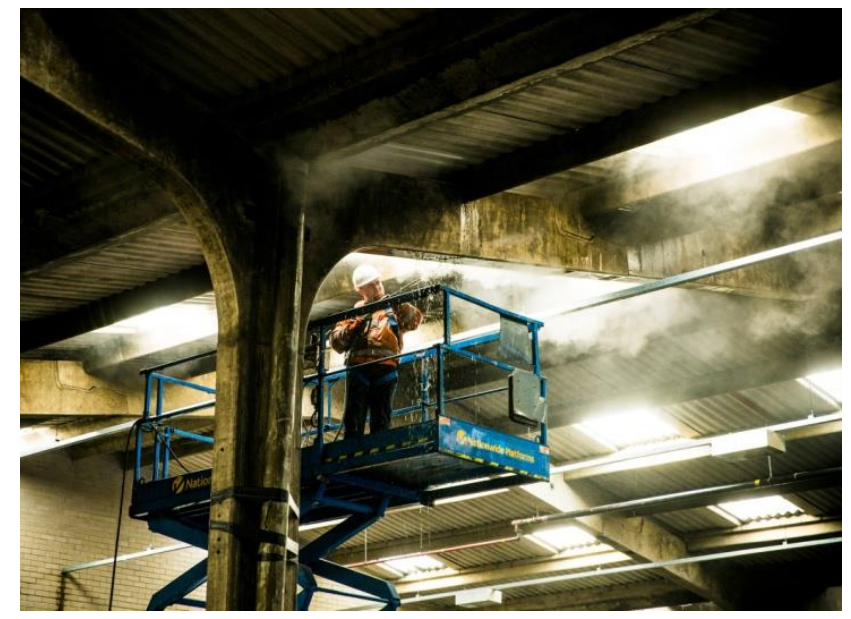

Fig. 1. Industrial cleaning.

The industry high roof cleaning needs to be at a low cost as compared to the available systems worth approximately 45lakhs of rupees, where small scale process industry finds it more costly to clean as per norms. The system should provide flexibility to the consumer for maintaining and handling. The weight of the pipe of cleaning for operator needs to be reduce to avoid other labor health issue and to also minimize time of cleaning.

\section{System Purpose}

Cleaning is very essential in every industry, as the dust can damage the products that are manufactured in the industry, and cause harm to the workers also. Industrial high-level vacuum cleaning includes the cleaning of industry walls, cleaning the ceilings of industry which contains dust particles, industrial scrap, spider webs, etc. We can also clean air conditioners and ventilation system.

\section{Objectives}

- The Industrial Cleaning using (HRDDCM) is the safest and most effective way of cleaning the high ceilings.

- (HRDDCM) system provides cleaning in less amount of time reduces large amount of man hours as compared to labor dependent large cleaning.

- This system reduces the overall efforts and weight handled while cleaning by the labor by providing support to the long length suction pipe.

\section{DESIGN CONSIDERATION AND IMPLEMENTATION}

In Industry High Roof Dry Dust Collector Machine (HRDDCM) is the safest and most effective way of cleaning the high ceiling, of industries up to the height of 15 meters, the walls of the industries and can be able to clean the ventilation systems. This machine can also clean the places which are hard to reach.

The designed machine is operated from ground level, so it is safer and cost gets reduced. Further we can adjust the wide range of specialist brushes, tools and accessories to efficiently clean the difficult to reach areas. It is able to operate the machine from the floor; it makes the system safer, quicker and cheaper high-level cleaning service. No ladders are needed as we have provided support of the metallic rod to the PVC vacuum pipes so that these pipes are stable. Less manpower is required. The overall weight of operator reduces while performing the operation of cleaning.

Design Consideration:

\section{A. COMPONENTS USED.}

Following are the hardware which are used for developing the proposed system.

1. Base unit: This base unit is designed in auto-cad first and then made up of iron angels and GI metal sheets, which moves on wheels joined at base. These wheels of base unit are propelled by a handle which moves the base unit forward and reverse respectively and turn using handle.

The doors are been designed and made in the base unit. For proper space utilization and to preserve special attachments of the system. 


\section{International Journal of Engineering Applied Sciences and Technology, 2020 \\ Vol. 5, Issue 2, ISSN No. 2455-2143, Pages 137-140 \\ Published Online June 2020 in IJEAST (http://www.ijeast.com)}

2. Vacuum impeller: The vacuum impeller is a vacuum generating motor with $23000 \mathrm{rpm} @ 230 \mathrm{VAC} 50 \mathrm{~Hz}$ 1300 watt. Such two impeller are been used to balance the required suction pressure.

3. Vacuum filter cloth: Vacuum filter is a 5-micron filter cloth used here to resist and to avoid the dust to enter the vacuum impeller

4. Dust collecting chambers: The dust collecting chamber is a cylindrical drum of capacity up to $70 \mathrm{~L}$ and in which the dust

5. Vacuum pipes: Flexible pipe, Non-flexible pipe:

\section{B. Mechanical Design of base unit}

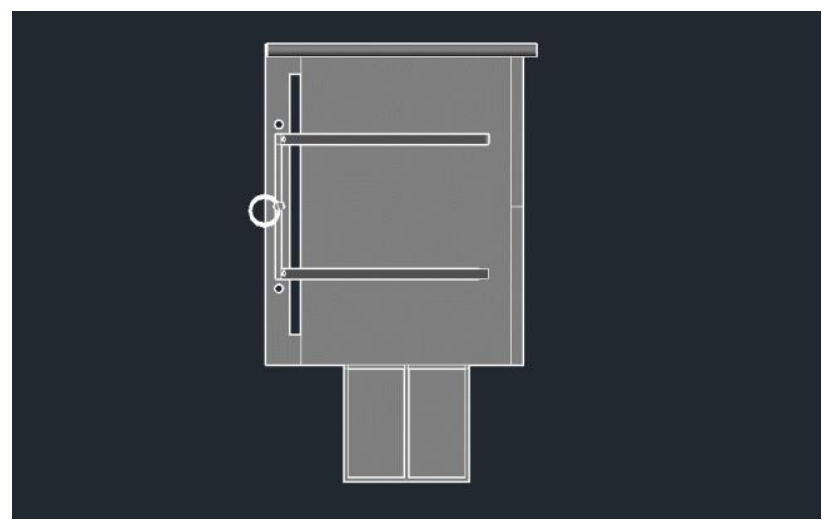

Fig-2(a) Top view

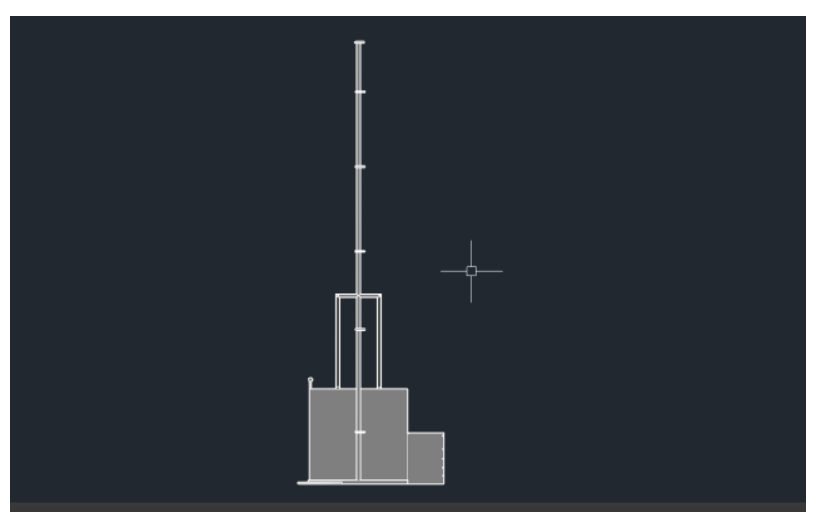

Fig-2(b) Front view

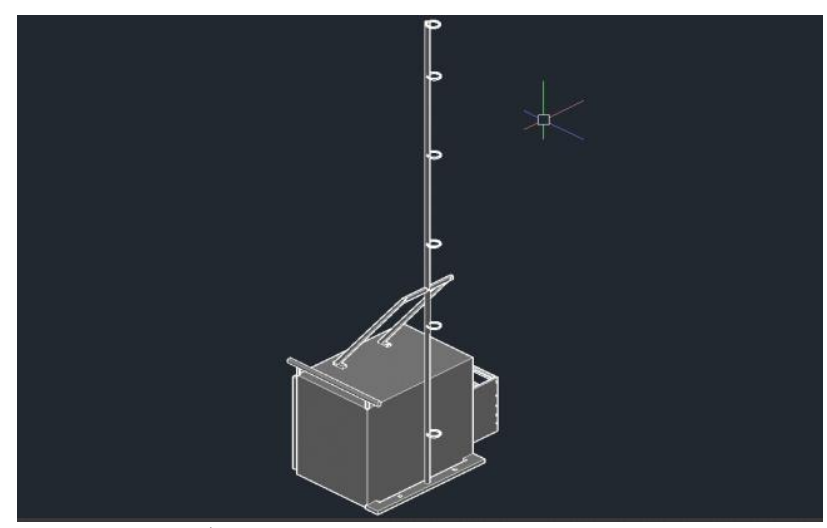

c) Isometric view.

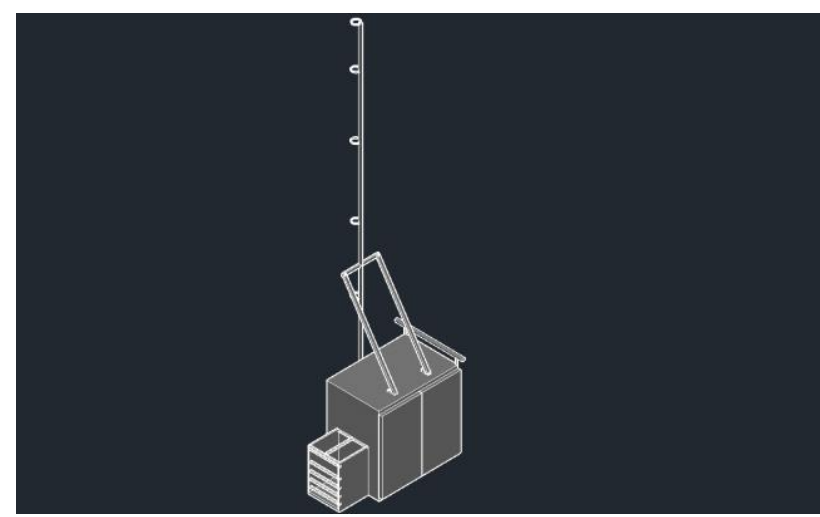

g

-2(d) South East Isometric view

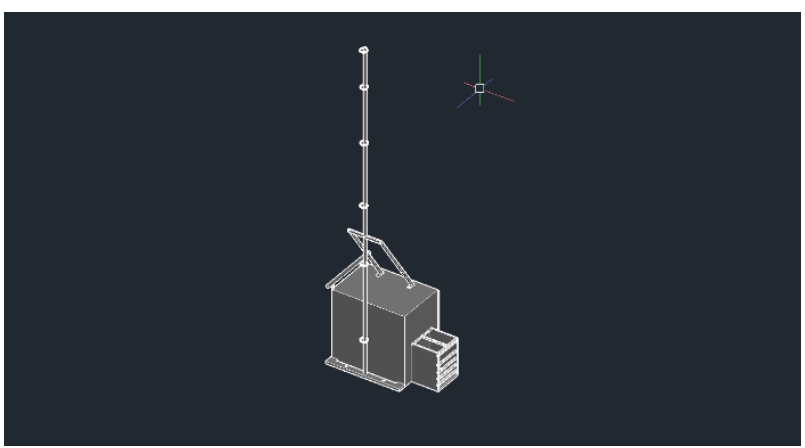

Fig 3: High Roof Duct Dust Cleaning System

\section{CONCLUSION}

The high roof cleaning system is so design on single phase supply operated manually. The iron pipe supporting assembly is assembled and then the vacuum pipe is pass to the required height. The vacuum impeller is then switched on manually through MCBS on control board.

The high roof dry dust cleaning machine can be propelled reverse and forward with help of base wheels adjusting the 
length of the pipe required and you can easily clean high roof shades.

\section{REFERENCE}

[1] US8347445B2 - Remote controlled robot for cleaning inner

[2] JP6091771B2 -Self-propelled electronic device and control system for self-propelled electronic device https://patents.google.com/patent/JP6091771B2/en

[3] Inventer John W. Ryan Duct cleaning apparatus Publication of United States Patent 1 Ryan et al (Apr. 2, 1974) US3800358A

https://patents.google.com/patent/US3800358

[4] Publication of US3854164A.et al (1990-12-12.) Assigned to whirlpool floor care corp., ("whirlpool sub") a corp. of Delaware

[5] Inventor Vincent L. Bobrosky Richard J. E i senmenger, US60I85382A - Air filtrating self-propelled upright vacuum.

https://patents.google.com/patent/US6085382

[6] JP 2007-34561 A

[7] References Cited UNITED STATES PATENTS Stanley $15 / 104.09 \mathrm{X}$

[8] Patty/Clayton GD, Clayton FE et al (1991). Patty's Industrial Hygiene and Toxicology, Clayton GD, Clayton FE, editors.

Volume I: General Principles, 4th edition. Part A, 1991, ISBN 0-471-50197-2; Part B, 1991, ISBN 0 471-50196-4. American Conference of Governmental Industrial Hygienists (ACGIH), Cincinnati, OH, USA.

[9] Zimmer, Comparative evaluation of dust control technologies on percussion rock-drilling rigs et al (1997). Applied Occupational and Environmental Hygiene 12(12):782-788.

[10] Charles A. Gallaer \& J. W. Schindeler et al (1963) "Mechanical Dust Collectors", Journal of the Air Pollution

Control Association, 574-580 